\title{
Of Meanings and Movements: Re-Languaging Embodiment in Dance Phenomenology and Cognition
}

\author{
Edward C. Warburton
}

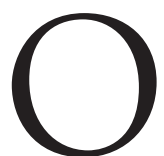

ne of my favorite childhood memories is from my first dance class. I ran into the studio and started jumping, jumping, jumping literally for joy when I noticed suddenly that I was not alone. There were other children in class, and they were all jumping too. We jumped together, spontaneously in sync, oblivious to what must have been looks of parental incredulity peeking through the door. The teacher stopped us well before anyone fell to the floor but not so soon as to mistake the extraordinary (teachable) moment. Human beings can bond together through rhythmical movement and expressions like joy, and dance is fundamentally about making those connections: to self, to others, to the world, and beyond. In sixty seconds, our little dance community was born.

If this anecdote hints in some way at the already-given condition in dance-of the lived human experience in dance and possibilities for transformation inherent therein-then it would seem a good starting point for the theorizing of dance consciousness and cognition. In fact, considerable interdisciplinary attention has been given to the study of dance as a unique window on human knowledge and experience. Beginning in the 1960s (cf., Sheets-Johnstone 1966), dance scholarship in particular has drawn heavily on programs of research founded by the German philosopher Edmund Husserl and advanced by the French philosopher Maurice Merleau-Ponty. ${ }^{1}$ Dance scholars have applied phenomenological methodologies to help explain various aspects of dance. This work has made significant and ongoing contributions to our understanding of, among other things, aesthetics; the expression and construction of identities; movement practices and the body; the politics of culture; reception and spectatorship; the role of dance in human histories and societies; and ritual practices (Daly 1992; Desmond 1997; Farnell 1999; Fraleigh 1987; Parviainen 1998; Reed 1998; Sheets-Johnstone 1999).

Phenomenology is essentially a philosophical argument for the foundational role that perception plays in understanding and engaging with the world. Although this approach to cognition provides an original perspective, the basic idea is actually very old (Prinz 2002). Early sources emphasizing an ideo-motor principle in thought and language found voice in William James's (1890) Principles of Psychology before they fell into oblivion due to the dominance of behaviorism in the first half of the twentieth century (for a review, see Stock and Stock 2004). Contemporaneous to Husserl was the developmental psychology of Jean Piaget (1952), which emphasized the emergence of cognitive abilities out of sensorimotor skills. What distinguishes Merleau-Ponty as an original thinker with

Edward C. Warburton is associate professor of dance at the University of California, Santa Cruz. His interest in phenomenology and cognitive science began after a professional dance career when studying for a doctorate in human development and psychology at Harvard University. Warburton is associate editor of Research in Dance Education (UK) and co-president of the California Dance Education Association (USA). 
particular relevance to dance studies is his depth of insight about the nature of corporeity, his methodological approach, and his openness to art disciplines outside of phenomenological philosophy. Merleau-Ponty's "phenomenology of embodiment" makes the physical (somatic) being the site of the psyche. The body determines what shows up in our world. The ecological psychology of J. J. Gibson (1979) deepened this insight by seeing the characteristics of the human world, e.g., what affords walking on, picking up, etc., as correlative with our bodily capacities and acquired skills. By embodiment, Merleau-Ponty (1962) indicates three ways that the body opens up a world—as innate structures, basic general skills, and cultural skills:

The body is our general medium for having a world. Sometimes it is restricted to the actions necessary for the conservation of life, and accordingly it posits around us a biological world; at other times, elaborating upon these primary actions and moving from their literal to a figurative meaning, it manifests through them a core of new significance: this is true of motor habits [sic] such as dancing. Sometimes, finally, the meaning aimed at cannot be achieved by the body's natural means; it must then build itself an instrument, and it projects thereby around itself a cultural world. (146)

Advanced by phenomenology and embraced by dance scholars, the term embodiment has since the mid-1980s also been used extensively in the cognitive science literature. Cognitive science is more of a loose affiliation of disciplines than a discipline of its own. Cognitive psychology, neuroscience, artificial intelligence, linguistics, and philosophy have all participated in a research agenda that, in its widest sense, views the study of mind in and of itself as a worthy scientific pursuit (Gardner 1985). Though cognitive science does not have a clearly agreed upon sense of direction, the concept of embodiment has become important in many research areas. Simply put, the embodiment thesis holds that "mental activity depends essentially not just on the brain but on the body as well” (Legrand, Grünbaum, and Krueger 2009, 279). Embodiment is nowadays by many cognitive researchers considered a condito sine qua non for any form of natural or artificial intelligence (Pfeifer and Scheier 1999).

If one could posit a singular through-line of this diverse research, it would be that bodily movement is essential to an understanding of all aspects of life. The resurgence of interest in the body within larger social and cognitive scientific circles is a remarkable paradigm shift; one can make a strong argument that dance scholars have agitated for such a shift for a long time (e.g., Foster 1996; Hanna 1988; Shapiro 1998). The problem with embodiment as a joint philosophical-scientific concept, however, is that there are very different notions of exactly what it is, what it means for different disciplines and ways of knowing, and what kind of body (if any) is required for an "embodied cognition" (Ziemke 2001). Indeed, the phenomenologist Sheets-Johnstone (2009) has made penetrating criticism of embodiment in her recent collection of essays (215). As the concept has circulated, it has lost explanatory power.

The purpose of this essay is to advance the current effort in dance studies to reconsider the relative contributions of, and possible correspondences between, phenomenology and cognitive science. It is a methodological question of re-languaging what is meant by embodiment. My agenda stems from three important contemporary trends: (1) a need to re-evaluate the critical basis of phenomenological analysis of dance, performance, and somatic movement practices (e.g., Engel 2008; Kozul 2007; Legrand and Ravn 2009; Parviainen 2002; Rothfield 2005; Rouhiainen 2003, 2008); (2) the movement in cognitive science to grant the body a central role in shaping the mind (e.g., Clark 1997; Gallagher 2005; Gibbs Jr. 2006; Thelen and Smith 1994; Varela, Thompson, and Rosch 1991; Wilson 2002); and (3) an explosion of interest among neuroscientists who view dance, for example, as a complex sensorimotor skill with unique neural organization (Birringer and Fenger 2005; Bläsing, Puttke, and Schack 2010). To understand better the thinking behind the doing of dance, I contend that it is important now to introduce critical perspectives and conceptual 
approaches that can reframe and "re-language" the role of movement and dance in human consciousness and cognition. The discipline of dance studies stands to benefit most from the current focus on the body, as long as the problem of how to "language experience" in dance remains a primary concern.

It is especially important to identify and unpack key concepts in dance for describing its psychological features. ${ }^{2}$ Because the psychology of dance experience remains in its infancy, we should address the assumption of diametrically opposed paradigms - separating a philosophy of human experience from a positivist scientific tradition — to avoid the further splintering of theory, research, and even performance practice into competing narratives. ${ }^{3}$ One finds such polarization in music, where "neuromusical research" contends with "musicking" to explain the "Mozart effect" (Bangerter and Heath 2004). Music research that takes a more phenomenological approach emphasizes the first-person "lived" experience of being a music-maker, for example, while those from a cognitive neuroscientific approach take a third-person objective perspective to understand the implicit brain processes behind music-making. (After all, the brain is part of the body, hence the recourse to embodiment.) The main effect is scholarly donnybrooks that do more to obscure than reveal important correlations. With few exceptions (Jola, Ehrenberg, and Reynolds 2011; Reason and Reynolds 2010), the research literature on arts cognition reifies this split.

The present essay charts a different path. By engaging a problem central to this research agendathe riddle of how dancing emerges from the somatosensation of organized movement-my goal is to help open up the phenomenology of dancing to the cognitive sciences and vice versa. In what follows, I examine the thinking behind the doing of Western theatrical concert dance (hereafter "dance"). I propose the theoretical construct of dance enaction to understand how experiences of dance emerge from more basic processes, and how dancing shapes the mind, body, and brain. The concept of "enaction" is a cornerstone of the embodied cognition literature, which claims that cognition is "for action"-i.e., the function of the mind is to guide action-and is a "situated activity"-i.e., it takes place in the context of a real-world environment. An enactive approach emphasizes the emotional and relational nature of thought in action. ${ }^{5}$ The conjoinment of "dance" with "enaction" defines the knowledge domain and real-world context of dancer action and performance. To underscore dance enaction as a content-rich construct, I employ a distinctly humanistic, theoretical stance toward thinking in dance using "talk from the body." I ask, what are some distinctive, relevant, and particular psychological concepts and processes in dance? I speculate about and unpack those concepts that have unique, dance-specific application, such as varieties of empathetic response (somatic, kinesthetic, and mimetic) and the phenomenon of dance "marking," in light of a rapidly growing body of research literature on dance action and perception. I conclude with some implications of the re-languaging of embodiment in dance as dance enaction, which I argue leads to some otherwise unattainable conclusions about the phenomenon of dance cognition.

\section{Dance Enaction}

Human beings everywhere engage in complex structured systems of bodily action that are laden with social and cultural significance. Language and gesture, movement and interaction, vision and audition, emotion and cognition all were involved in the development of the human mind as we know it today (Donald 1991). Dance was and is necessary precisely because it engages all aspects of the brain, body, and mind. Despite the centrality of dance in human experience and the proliferation of dance studies, there has been little effort to advance a psychology of dancing. How do dancers construct and integrate all the necessary information to perform highly sophisti-

cated physical tasks, lined up in hour-long choreographies that have to be flawlessly remembered, at the same time producing expressions of deep emotional quality that have the power to communicate to others? Some consider dance as "thought made visible," but fail to provide an adequate, 
domain-specific account of how the candidate cognitive processes that underpin dancing differ from gesture communication, or musical or athletic performance (Stevens and McKechnie 2005). The lack of investigation stands in stark contrast to the extensive literature on the psychologies of music and visual arts (e.g., Hallam, Cross, and Thaut 2009; Solso 1994), and the burgeoning literature on a psychology of acting and directing (cf., Goldstein and Bloom 2011; McConachie and Hart 2006).

\section{Enacting Talk from the Body}

To be trained as a dancer today is to be enculturated into a world of meanings and movements. The quintessential experience of dancing brings with it a sense of beingness in the here-and-now-a sensation through which one can perceive connectedness in movement, can locate the body in three-dimensional space, can feel togetherness in time, and can know a oneness with a larger entity that humans often identify as transcendent religious experience. Dance is thus an ideal medium for investigating embodiment, and considerable attention has been given to "talk about the body" as cultural object, to "talk of the body" as subjective experience, and, more recently, to "talk on the body" as architect of the human mind (Damasio 1994; Desmond 1997; Farnell 1999). These contemporary accounts often assume that experiences of dance, like other human behaviors and mental events, are entailed or instantiated by either physical processes in the brain-body or cultural processes in society. In principle, these assumptions must be correct, since dance can be explained by events in the physical or social world. But materialist accounts often go one step further by assuming experiences can be redefined as nothing but these causes, and therefore must be understood solely in terms of them. ${ }^{6}$

An adequate account of dance experience requires more than a specification of cause; it requires a description of the content (i.e., what is felt/thought) that is common to all experiences of dance and that distinguishes one experience from another. As suggested by John Searle's (2004) philosophical framework called biological naturalism, it is clear that dance content cannot be entirely reduced to its causes. The experience of dance is a culturally embedded event. It is also, like any conscious state, a system-level property of the brain, the physical basis of which can be explained by neuronal activity, much as digestion is a system-level property of the gastrointestinal system that can be explained causally by the chemistry of the body. Dance may be explained partly by neurobiological (material) features. It may be explained in part by societal, cultural, and historical influences. But it cannot be ontologically reduced to any single material cause; to conflate these different levels of analysis is to make a category error (Ryle 2000). Dance as conscious event, whether deploying implicit (procedural) or explicit (declarative) knowledge, has both neurobiological and phenomenological features. For example, the claim that knowing the causes of emotion in dance is sufficient to answer the question of what emotional experience in dance is like no longer holds up to the lived reality that people feel something (such as joy) when they experience dance. Such explanations leave out of account what it is like to perform, watch, or make dance. Human consciousness exists only from a first person, ontologically subjective, point of view. To know what dancing is or feels like, one must ask dancers what they experience or experience dance oneself (cf., Jackson 1982, for the "knowledge argument"). Questions about material underpinnings of experience will never reveal the entire story.

This perspective suggests a method that generates insight into dance experience by taking an "enactive" approach in the investigation of "talk from the body." Talk from the body was first proposed by anthropologist Drid Williams (1991) as a way of understanding dance as dynamically embodied action in semantically rich spaces. In my updated formulation, I argue for locating talk from the body in those dance ideas that uniquely describe a content-rich pragmatics of cognition (versus a content-poor mechanics of information processing, cf., Baltes, Staudinger, and Lindenberger 1999). Content-rich concepts emerge at the level of psychological description and are causally 
constituted by neurobiological processes. As discussed in a later section, a concrete example of talk from the body is the dance-specific (i.e., emic) concept known as "marking." Literally "to mark time," it is a memory device that dancers employ to mark particular moments in the dancecompressing their movements in space and chunking sequences in time-in order to commit to memory long passages of choreography. (Choreographers understand this need and often tell dancers not to dance "full out" but to "mark it.") Marking is part of the practice of dance, pervasive in all phases of creation, rehearsal, and reflection. Virtually all English-speaking dancers know the term, though few scholarly articles exist that describe it. Dancers are not taught to mark in any formal sense. Dancers devise their own personal marking system, developed and elaborated over time, which makes it prototypical talk from the body behavior.

Enaction is a word derived from the verb to enact: "to start doing," "to perform," or "to act." The basic principles of an enactive approach to human behavior were first outlined by Varela, Thompson, and Rosch (1991). They describe and unify under one heading several related ideas:

The first idea is that living beings are autonomous agents that actively generate and maintain their identities, and thereby enact or bring forth their own cognitive domains. The second idea is that the nervous system is an autonomous system: it actively generates and maintains its own coherent and meaningful patterns of activity ... [it] does not process information in the computationalist sense, but creates meaning. The third idea is that cognition is a form of embodied action. Cognitive structures and processes emerge from recurrent sensorimotor patterns of perception and action. Sensorimotor coupling between organism and environment modulates, but does not determine, the formation of endogenous, dynamic patterns of neural activity, which in turn inform sensorimotor coupling. The fourth idea is that a cognitive being's world is not a pre-specified, external realm, represented internally by its brain, but a relational domain enacted or brought forth by that being's autonomous agency and mode of coupling with the environment. This idea links the enactive approach to phenomenological philosophy, for both maintain that cognition bears a constitutive relation to its objects. (Thompson 2005, 407-408)

I find the enactive approach an especially powerful theoretical lens for understanding dance thought in action for three main reasons. First, it posits a mental model that encompasses three intertwined modes of bodily activity — modes that resonate with three intertwined realms of dance experience: self-regulation (somatic realm), sensorimotor coupling (kinesthetic realm), and intersubjective interaction (mimetic realm) (Cohen 1993; Kimmerle and Côté-Laurence 2003; Press 2002). Second, the enactive approach emphasizes the roles of emotional and relational experience in meaning-making. It underscores the many ways emotion and cognition are linked from early perception to higher order reasoning (cf., Phelps 2006). Finally, its explanatory power lies in the ways it treats distinct claims in approaches to embodied cognition-claims that are not accounted for adequately by psychology or phenomenology alone. For example, one can distinguish on-line (time pressured) aspects of embodied cognition from off-line (mental simulation) aspects. Traditionally, the various branches of cognitive science have viewed the mind as an abstract information processor, whose connections to pressures of the outside world are of little theoretical importance; the ideal cognizer steps back, observes, assesses, plans, and takes action (or not), and then reflects on what happened. Phenomenological accounts of "lived" experience, on the other hand, tend to view cognition as primarily in-the-moment and on-line; by definition, the situated being is an ecologically oriented one who is in near constant interaction with the things that the cognitive activity is about (Gibson 1979).

Because the enactive approach views knowledge as constructed in action through emergent and selforganizing processes, it can account for the workings of both online and offline cognitive (and 
emotional) processes simultaneously. Consider, for example, a dancer "marking" a movement during the process of learning a new combination. As any dancer can attest, this activity often demands fast and continuously evolving responses to rapidly changing conditions. At the perceptuo-motor level, movement coordination requires continuous reciprocal influence between perceptual flow and motor commands; the dancer is undeniably situated in relationship to self (and instructor) and thinking "in real time." At the same, the dancer is manipulating her environment, for instance using movement reductions such as a small hand gesture to indicate a turning movement on count eight, to exploit predictability in the task situation and automatize what was a formerly effortful process of skill acquisition. In short, she can use her implicit memory to prime in correct sequence a "turning" motor program by taking it off-line. ${ }^{7}$ The fact that the success of this activity depends crucially on each individual's own cognitive mapping of somatic, kinesthetic, and mimetic knowledge and skills underscores the ways dancers actively generate and maintain their identities, and thereby enact talk from the body in a unique cognitive activity such as dance marking.

\section{Relevant Literature}

In thinking through dance enaction from the body, close examination of two questions is key. The first question, "What do dancers experience when they experience dance?" is the question of content. Over the past several decades, an extensive literature covering major thinkers and figures in dance highlights it as a content-rich cognitive, emotional, and relational event (Press and Warburton 2007). Since the mid-1990s, empirical research in America has focused on doing dance and the self-awareness, learning, and teaching that enhance (or undermine) dancers' experiences and their abilities to convey the intention and feeling of the works they perform (e.g., Bond and Stinson 2000/01; Eddy 2009; Warburton 2003, 2004). Internationally, researchers have considered the role of cognition in the making and viewing of dance. These projects include choreography and cognition (McCarthy et al. 2006); choreographic thinking tools (Ede 2006, 2008); distributed choreographic cognition (Welsh 2009); thinking in four dimensions (Grove, Stevens, and McKechnie 2005); and watching dance (Wildschut 2010).

The second question - "How does the brain instantiate dance experience?"-is the straightforward but difficult question of how neurophysiological events constitute phenomenological content. Over the last decade, cognitive and neuroscientists have turned to dancers as a valuable human resource in possession of a rich skill set who can be studied to address broadly relevant issues of how the human brain coordinates perception with action (Birringer and Fenger 2005). The recent interest is rooted in the discovery of mirror neurons (Rizzolatti et al. 1996). Mirror neurons fire both when an animal acts and when the animal observes the same action performed by another. In this way, the neuron "mirrors" the behavior of the other, as if the observer herself were acting. Such neurons have been directly observed in primates, humans, and birds, with a steady increase in published research on motor simulation in the human brain generally consistent with that of the mirror neuron system (MNS) (Cross 2010). ${ }^{8}$

The possible roles of the MNS are still a matter of debate. Many investigators agree that mirror neurons may support understanding of what action another individual is performing and how it is being performed (Thioux, Gazzola, and Keysers 2008). Anyone seeing a person's hand reach for a cup of coffee will recognize the goal of the action: reaching to grasp. This mirroring seems to occur primarily at the level of motor goals. Here in the topic of movement intention and observation is the place where dance has become so important. Some of the experiments investigate motor simulation using dance as a visual stimulus or motor stimulus in brain imaging experiments (Brown, Martinez, and Parsons 2006; Calvo-Merino 2010). Behavioral studies have compared expert dancers versus novice dancers to examine cognitive processes such as body representation

(Ramsey and Riddoch 2001), movement representation (Bläsing, Tenenbaum, and Schack 2009), 
mental transformation and imagery (Golomer et al. 2008; Jola and Mast 2005), and visuo-motor coupling in motor control (Golomer and Dupui 2000). Researchers also draw on dance in studies of brain processes involved in motor synchronization (Orgs et al. 2008); perception of human motion; movement control; and the way movements are initiated, adapted, and stored in memory (Schack 2004; Schack and Mechsner 2006). It is thus becoming possible to sketch the neural circuitry and cognitive processes that become active during certain types of content, including dance. It is important to note, however, that cognitive neuroscience has turned to dance to learn how the human brain coordinates perception with action, and not to understand dance cognition per se, hence the need to assert a theoretical framework such as dance enaction that locates front and center dance content, cognition, and consciousness.

As a whole, recent research has provided crucial insights into dance enaction. Of specific relevance is the burgeoning area of research on imitation and empathy, both functions attributed to the MNS (Catmur, Walsh, and Heyes 2009; Gazzola, Aziz-Zadeh, and Keysers 2006). What one finds is a number of unique psychological concepts and processes relevant to dance, many of which are mentioned across diverse contexts. Some concepts are explicit and have long histories, such as marking. Others have implicit, perhaps even prenoetic characteristics (Gallagher 2005), such as somatic empathy, the recently (re)popularized notion of a kinesthetic empathy, and the much less discussed, but just as important, notion of mimetic empathy. Because it enjoys a rich (and complicated) history in the phenomenological and scientific literatures, empathy is of particular interest in light of dance enaction. Empathetic response is arguably what most differentiates dancing from other skilled physical activities, such as running and sports; furthermore, the varieties of empathetic response in dance are arguably what distinguish dance from other performing arts (Foster 2011).

\section{From Motor Resonance to Empathetic Response}

Human beings have a remarkable capacity to intuit the mental states of other individuals. If we see a dancer move into a big first arabesque and suddenly grab at her back and grimace, we sense immediately that she is not enjoying her dancing. Just the sight of her pain might cause us to wince and prevent us from ever trying the movement. Though someone's more subtle emotions can be perplexing, we often have gut feelings of what is going on in others. Sharing the feelings of others, defined here as "empathy," is only one part of a large spectrum of a person's possible vicarious responses toward others. Related terms such as compassion, sympathy, and emotion contagion all suggest an affective response to the directly perceived, imagined, or inferred feeling state of another being. In my own understanding, empathy occurs when I perceive or imagine someone else's affect, and this triggers a response such that I partially feel what that person is feeling. De Vignemont and Singer define empathy as follows: "We 'empathize' with others when we have (1) an affective state (2) which is isomorphic to another person's affective state, (3) which was elicited by observing or imagining another person's affective state, and (4) when we know that the other person's affective state is the source of our own affective state" $(2006,435)$.

This definition of empathy suggests a perception-action, direct-matching model found in social cognition theories that rely on MNS accounts. Decety (2010) raises some doubt about the shared representations account of empathy, which is still the dominant neuroscientifically motivated approach to understanding the mechanisms underlying empathy. But there is mounting evidence to suggest that a similar neural mechanism involved in action imitation may also apply to the domain of sensations. Several neuroimaging experiments show that common circuits in the human brain are activated when observing sensations or emotions felt by others, and when experiencing these sensations and emotions ourselves (Bastiaansen, Thioux, and Keysers 2009). Many researchers believe that the MNS plays a central role in at least one component of empathy: namely, sensorimotor resonance in human beings (Avenanti et al. 2005). It is here in a "bottom-up" 
approach to empathy that I find it possible to speculate on the contributions of resonant action systems and motor mimicry to different empathetic responses in dance. What could be the role of this automatic cortical simulation, especially for those, like actors and dancers, who are trained to access and express emotion?

In the study of the neural underpinnings of perceptuo-motor abilities in dancers, cognitive neuroscience has shown that observing others' actions involves both a covert simulation of the very same action - a process crucial in imitative motor learning - and a modulation of resonant action systems that seem to be important in superior perceptual abilities. Transcranial magnetic stimulation studies, for example, show that the mere observation of an action, like a first arabesque, induces a selective increase of motor-evoked potentials from the muscles that would be active if the observed actions were performed (Fadiga et al. 1995). Moreover, such mirror motor activation is greater for "familiar" than "unfamiliar" actions (Calvo-Merino et al. 2005). Neuroimaging studies take this one step further by showing the influence of motor expertise: brain activity has been found to be higher in individuals who had direct and sustained motor experience of the observed dance moves. Imagine you are a professional ballet dancer. You have obviously performed a first arabesque many times. When you see a first arabesque performed, your (neural simulation) response not only will be stronger than a non-dancer's, it also will presumably be stronger than a beginning ballet dancer's (Calvo-Merino et al. 2006; Cross, Hamilton, and Grafton 2006; Cross et al. 2009). This finding may seem obvious to those of us who have danced or watched a choreographer go twitchy while watching her dancers perform, but it is remarkable nonetheless to find such a powerful response at such a basic somatic level.

Taken together, these results suggest that professional dancers (and former dancers) know more, experience more in a bodily sense, than the average person even when simply watching dance. Studies on elite athletes show similar results, providing psychophysical and neurophysiological evidence that they can predict the fate of an action by reading body kinematics and incorporate finegrained details of the observed actions (Aglioti et al. 2008). Expert basketball players watching someone shoot from the free-throw line can more accurately predict, the instant the ball leaves the person's fingertips, whether the ball will fall through the net than amateurs can. Clearly, expertise in physically demanding activities requires an extremely tight link between embodied mapping and visual readout of observed actions.

In dance, these modulation and mapping capacities play an especially important role in the development of somatic and kinesthetic responses and, by extension, mimicry. ${ }^{9}$ In psychological terms, mimicry is defined as the tendency to automatically (often unconsciously) synchronize affective expressions, vocalizations, postures, and movements with those of another person (Singer and Lamm 2009). The general understanding of mimicry as a low-level mechanism contributing to empathy derives from a multitude of studies using facial electromyography (fEMG), a technique that measures muscle activity by detecting and amplifying the tiny electrical impulses that are generated by muscle fibers when they contract. These studies demonstrate that when an observer perceives another person's affective facial expressions, such as a smile or a frown, corresponding affective expressions result in the observer (Dimberg and Öhman 1996). On a conceptual level, however, mimicry alone cannot account for the full-blown experience of empathy, because empathy crucially depends upon self-awareness and self/other distinction.

The study of the neural basis of simulation shows how emotions are in some sense shared through a mosaic of motor, somatosensory, and affective simulations that activate corresponding representations in another person. But people's empathetic responses differ in important ways. As suggested above, certain people or groups of people may engage, or be trained to engage, in more motor or affective simulation at different times and for different tasks. Indeed both the phenomenological and cognitive science literatures support the idea that empathy is not a unitary system. Consider the difference between three main divisions, each reliant on at least partially dissociable neural 
systems: motor, affective, and cognitive empathy (Blair 2005). As described above, motor empathy is defined as the tendency to automatically mimic and synchronize movements with those of another person. The perception of the ballet dancer's back pain, for example, activates my corresponding representations (personal experiences of dance and back pain), which in turn can activate somatic and autonomic responses that make her pain in some sense "felt" by me (Avenanti et al. 2005). Cognitive empathy (also called "theory of mind") refers to the ability to represent the internal mental state of others, i.e., their thoughts, beliefs, desires, intentions, and knowledge (Leslie 1987). Emotional empathy is a response to the emotional displays of others, i.e., their facial and vocal expressions and body movements, and other emotional situations, such as a response to hearing about a friend injure her back (Adolphs 2002). The research suggests that these three forms of empathy share a degree of anatomical overlap, but can operate independent of one another (Blair 2005). I suggest that these three kinds of empathetic responses provide additional empirical support for phenomenological accounts of dancing, where "feeling in" movement (somatic empathy) provides a foundation for the "feeling of" (kinesthetic empathy) and "feeling for" (mimetic empathy) in dance.

\section{Feeling "In," "Of," "For" Dance}

The argument for two intertwined features of dance enaction-the more cognitive (observation, simulation, imitation, execution) and more emotional (aroused, attentive, felt, expressive) aspects of movement-is supported by ideas about the nature of the dance experience. It has been argued for instance that dance, though it has a visual component, is fundamentally a kinesthetic art whose apperception is grounded not just in the eye but in the entire body (Daly 1992; for an alternate view, see McFee 1992). This observation underscores why in dance our resonant action (motor) systems and mapping of observed actions are tightly coupled with a sophisticated synchronization of movement and emotional display. Dancers as interpretative artists must be able to both physically reproduce a choreographer's movement vocabulary and faithfully represent her expressive intention. When dancers are successful, viewers not only see the movement, but they also feel its expressive intent. Simply put, dancers and viewers must move into empathy together. ${ }^{10}$ How? I speculate that three distinct forms of empathetic experience in dance-somatic, kinesthetic, and mimeticemerge from motor resonance and mimicry mechanisms.

The source of empathetic experience in dance is fundamentally somatic. The idea of somatic awareness has a rich history in movement practices (e.g., Chaiklin and Wengrower 2009; Cohen 1993). Early somatic movement practitioners such as Moshe Feldenkrais emphasized learning to "listen and respond to one's inner experiences, which is one's felt-level experience" (Corcoran 1981, 35). Contemporary somatic practitioners and educators have described this bodily based sensing of one's own and another's somatic experience as somatic empathy: "Practitioners of somatic education thus demonstrate a kind of empathic connected knowing that allows them, through mindful and sensitive touch, to know how to help their 'students' or 'clients' learn, with or without verbalization, while guiding their movement (Cheever 2000, 16). Experienced dancers will often talk about how they sense things in the body movements of others that non-dancers screen outsome signal or vibration, some sensory cues about another's state or intention. Veteran dancers of a particular choreographer say that they can sometimes sense what is going to happen, where the choreographer is physically headed (if not choreographically or thematically), before it happens. Researchers on Tourette's syndrome, a disorder of the nervous system, describe patients with an acute somatic empathy (Leckman et al. 2006). Tourette's symptoms of involuntary tics are characterized by a build-up of tension intensified by certain kinds of sensory overload that result in a visible release of energy - a state of mind that can remind one of the kind of intense focus required in dance to "center" oneself bodily and perform feelingly with others, especially on a high-pressure opening night. 
The foundation of somatic empathy, a "feeling in" dance, emerges from the motor empathetic response and sets the stage for more sophisticated responses. For example, expert dancers and teachers believe that one of the most important qualities in a dancer is a "feeling for" the movement, which dancers themselves describe as connecting to the choreography and by extension the audience (Warburton 2010). This ability is a kind of mimesis that is more appropriately characterized as mimetic empathy. This term emphasizes not just some simulated, outward mimicry, or aping, but something deeper and more intense. Perhaps a form of cognitive empathy, it is the ability to put oneself imaginatively in the place of another, reproducing in one's own imagination and physicality the emotional tenor and movement form of another. Willerslev (2004) describes such an experience in his ethnography of the Yukaghirs, indigenous hunters in Siberia, who believe that humans and animals can turn into each other by temporarily taking on one another's bodies:

By mimicking another's bodily behaviour, senses, and sensibilities empathetically, I can assume the quality of the Other's perspective, because although the experiences that I come to share with the Other through practices of mimetic empathy are imagined as shared, they are not fictive. By this I mean that they are not pure fantasies, but acquire a sense of "reality" through their connection to my lived body.

Thus the nature and role that mimetic empathy plays in a dancer is not mere representation, but a materiality grounded in bodily experiences of the choreographer's way of dance-making, which, through mimetic mirroring of movement qualities and emotion and intent, becomes a shared vision both in actual presence and, possibly, in actualizing absence (Franko 1995; Franko and Richards 2000). In this way, mimetic empathy is not only a re-presenting or re-imagining, but has a decisively corporal, physical, tangible quality from which the dance ultimately emerges and from which it derives aesthetic, cultural, historical, and social significance.

For spectators, on the other hand, to watch dance is to have a "feeling of" the movement, simulating movement sensations of the dance. Observers of dance are in some sense "virtually dancing along" (Hagendoorn 2004, 95). A kinesthetic empathy suggests that when, even while sitting still, dancers (and others) can feel they are participating in the movements they observe. An important historical source for the idea of kinesthetic empathy is Theodor Lipps's theory of "Einfühlung." He argued that, when observing a body in motion, spectators experience an "inner mimesis." In the early twentieth century, kinesthetic empathy and related ideas took on particular relevance in the context of modernism, which emphasized the idea that receivers should respond directly to the medium of a work of art rather than to a story line or subject matter. In America, Lipps's ideas were taken up and developed by the influential dance critic John Martin, who argued for a kinesthetic sympathy or "metakinesis" that left traces associated with emotions in the neuromuscular system. Martin's belief in a literal physical transfer of feelings across bodies in dance has been criticized on grounds that it "universalized the personal and essentialized the irrational" (Franko 2002, 61). Contemporary cognitive-neuroscientific research makes no claims about direct transference of feelings, but it has revived interest in kinesthetic empathy as a kind of covert simulation of physical action that may reach a level of conscious emotional response-a form of emotional empathy as it were, at least for expert dancers and perhaps for longtime viewers as well.

As concepts that suggest essential structures and contents, varieties of empathy in dance provide a fertile ground for examining important aspects of dance enaction. Indeed, this essay thus far has dealt primarily with ideas about contents and structures-building blocks and design principles, if you will—of dance and those that enact dance. I believe that these building blocks are necessary. I have no reason to believe that I have defined the complete set. I have good reason to believe that it is not complete nor will ever be. My aim is to produce ideas that are interesting, significant, and clear enough to justify the hard work of investigation. So, while necessary, these contents must be put back into cognition and context to be found sufficient to explain some aspects of dance 
enaction. They must be put, in some sense, to the test. Marking in dance is uniquely suited to this task. As a dance-specific concept, it is one in which kinesthetic and mimetic skills and empathetic responses would seem to play an essential role.

\section{Dance Marking}

Consider that many skilled physical activities are sometimes performed in a reduced form that contrasts in predictable ways with normal performance. Examples include whispering and subvocalizing, in contrast to speaking out loud; "whispering" in sign language, in contrast to normal-scale signing; and "marking" in dance rehearsals, in contrast to dancing "full out." Several questions of interest arise from this phenomenon. One set of questions involves how marking looks in different contexts with different styles of dance. For example, a dancer who marks ballet may do so in a fundamentally different fashion than one who marks contemporary dance. She may also think and feel-kinesthetically and mimetically_fundamentally differently about it.

Another set of questions might ask about the ways in which movement reductions occur, the purposes of such reduction, and how a movement can be altered and still be considered the "same" movement. For example, when signed languages are whispered, the signs may be displaced to a very low location in the signer's signing space, disrupting a supposedly defining feature-hand location-of many signs. Yet this whispering is readily understood by other fluent signers (Wilson 2001). As a different example, marking in dance serves no communicative function and is not formally taught, and so each dancer may establish his or her own "vocabulary" of reduced movements to represent the fully formed movements. The purpose of reduction in whispering, for example, is to alter communicative functions. In other cases, such as subvocalization or reduced gesturing or pointing movements, the purpose may be purely internal, to aid the cognition of the individual without regard to others.

Marking in dance is particularly interesting in this regard. Nominally, the purpose of marking is to conserve energy. However, elite-level dance is not just physically demanding but cognitively demanding as well. Learning and rehearsing a piece requires concentration on many aspects of the desired performance, from the most basic elements of accurate body positioning and correct timing, through higher-level chunks of choreographic phrasing, to more subtle features of performance expression such as conveying "flow" and "weight" in specific ways at specific points in the choreography. A dancer who is rehearsing must concentrate not only on all of these features, but also on the physical demands of the movements, such as maintaining balance, which may also impose a cognitive load. Thus, marking may serve not only to conserve physical energy but may also relieve cognitive load (Cowen 2000). Many dancers develop marking systems that are highly representational, rather than just miniaturized performance, such as using a finger movement to represent a turn while not actually turning the whole body. These strategies may allow dancers to rehearse some aspects of the performance while not needing to allocate attention to other aspects.

In a recent study - the only one of its kind to be found - David Kirsh (2010), together with colleagues from Random Dance (United Kingdom), explored marking as a technique used by dancers and choreographers to think about dance phrases. They identified various forms of marking with three distinct functions: marking-for-self, marking-for-others, and joint-marking. Kirsh argues that marking, as a partial version of a movement phrase, is a form of "physical thinking" that allows a dancer to understand something deeper about the phrase's structure than through imagination or mental imagery alone: "[Dancers'] performance of a marked phrase is part of their ongoing process of grasping the phrase ... dancers do think about their phrases without dancing them or marking them. But, by marking-for-self dancers think better about their full-out phrase" (2010, 2868-2869). 
Indeed, it may be that the need to understand "something deeper about the phrase" originates from the empathetic imperative in dancing. Consider elite-level dancers working with a contemporary choreographer on a new work. Those who move along with a choreographer in real time may mark aspects of a sequence to recall motor goals in an off-line way, just so that they remember what goes where and when. But ultimately one of their main goals is to embody, as quickly and clearly as possible, the creator's expressive intention. Whether or not they are explicitly aware, expert dancers must move into empathy with other dancers, the choreographer, and the dance vocabulary (e.g., use of space, time, and energy). The objective is not to screen out but to allow in all signals, as many sensory cues as possible, so that dancers can feel and anticipate, perhaps even generate, expressive movement that somehow corresponds to the dancemaker's vision. When the choreographer asks them to stop and watch, they must feel they are participating in the movements they observe. In imagination and physicality, dancers must produce and reproduce in iterative fashion the emotional tenor and movement form of the particular dance.

Marking can thus be understood as much more than an energy saving device or form of "physical thinking." Marking a phrase may in fact provide a scaffold to mentally project more detailed structure onto the architecture and poetry of the dance. As an example of dance enaction, marking can be viewed as a unique dance tool that—in its most advanced form-puts cognitive and psychomotor processes in the service of empathetic response and ultimately movement expression. Marking in dance exemplifies, reduces, and reflects the psychological and physical complexity inherent in dancing without oversimplifying or trivializing it.

\section{Implications}

My goal in this wide-ranging essay has been to critically reappraise the relationship between phenomenology and cognitive science in light of contemporary interest in the thinking behind the doing of dance. By situating dance in a larger discussion of causes and contents, concepts and constructs, I hope to begin to understand how the experience of dancing emerges from a continuous stream of evolving affect, conceptual processing, physical sensation, and psychomotor skill all bound together in time and space to create connections between individuals and ideas. Rather than adopt an intermediary entity such as embodiment that would attempt to bridge the explanatory gap between cognitive science and phenomenology, I plumb the gap by re-languaging embodiment within a coherent and contextually rich background theory-i.e., thinking through dance enaction from the body-that "supports and explicates the connections that actually exist among the elements of an embodied cognitive system" (Gallagher 2005, 6).

Re-languaging embodiment in dance as dance enaction leads to some otherwise unattainable conclusions about the phenomenon of dance cognition. On the one hand, dance enaction enlarges phenomenological inquiry, in that it probes the complex relationships between the object of the dance and the subject who dances. The example of dance marking as notating-in-action flows from the sensation of moving and also reflects the way in which the imaginary or actual objects in the dance flow from and into the subject's movement. Dance marking marks "the very manner in which the object is kinaesthetically perceived by, and danced from, the subject's consciousness" (Stewart 1998, 49). However, instead of embodying the subjective unity of mind-body prized by dance phenomenology, this activity highlights how "one's body's physicality may express one's body's subjectivity" (Legrand and Ravn 2009, 390). Rather than cordoning off subject from object in a traditional phenomenological manner, the physicality of marking is experienced as an intrinsic part of the dancing experience of the moving subject as she develops feeling in, of, and for the dance. ${ }^{11}$ In this way, the activity itself is a kind of physical re-languaging. Perhaps that is the reason dancers find it such a useful device. 
On the other hand, dance enaction further problematizes the concept of embodiment for cognitive scientists more interested in cognitive processing capacity than meaning-making. The activity of dance marking not only allows for subjectivity to be accessible through the perceptual appearance of physical body "movement reductions," but it also can account for the workings of both on-line and off-line cognitive (and emotional) processes simultaneously. The marking dancer is moving and thinking explicitly in real time, at the same time using small hand gestures and her implicit memory to prime in correct sequence a "turning" motor program by taking it off-line. But, ultimately, marking is "for" expression, not faster information processing. It is a far different activity than one that would simply save physical effort. Dance marking activity reveals the power of an embodied mind understood as both "outer" and "inner," biological and phenomenological: "It encompasses both the body as a lived, experiential structure and the body as context or milieu of cognitive mechanisms" (Varela, Thompson, and Rosch 1991, xvi).

In the end, the existential concern that animates this essay results from tangible demonstrations in dance studies that have resisted, either tacitly or explicitly, the opening of a space of possibilities in which the circulation between cognitive science and phenomenology can be fully appreciated. What I aim to communicate is a pragmatic orientation-one that seeks to foster the transformative possibilities of human experience in a scientific culture and vice versa. This orientation has found an appreciative audience in theater studies. In the Preface to Performance and Cognition: Theatre Studies and the Cognitive Turn, McConachie (2006) argues forcefully for more research that combines scholarship in performance studies with cognitive studies, which he believes will lend to the field of theater "a better epistemological grounding for their truth claims" (xiv). Truth claims aside, in America today, the lack of investigation on thinking in dance has become especially noteworthy as dancers, choreographers, and educators are increasingly asked to provide more cognitive justifications-along with cultural, economic, and historic reasons-for the role of dance in American society and education (cf., Dana Foundation 2008). I maintain that the impediment of competing ideologies and approaches in dance studies no longer needs to be a roadblock to this great task. Contemporary dance scholars and practitioners-all dance enactors - are well suited to navigate the territory ahead.

\section{Notes}

I would like to express sincere gratitude to Mark Franko, the anonymous peer reviewers, and members of the American Society for Theatre Research's Working Group on Cognitive Science in Theatre and Performance. Without their interest and help, I could not have worked out my ideas as fully as they are here set forth.

1. I am thinking particularly of Husserl's Ideas: General Introduction to a Pure Phenomenology (1931) and Merleau-Ponty's early works, Phenomenology of Perception (1962) and The Structure of Behavior (1963).

2. Lambie and Marcel (2002) drew attention to the importance of unpacking the correct concepts for describing the psychological features of a system in their analysis of emotion experience.

3. Consider Hagendoorn's (2003) description of "principles of perception" in improvisation. Examples can be found on his Web site, http://www.ivarhagendoorn.com.

4. Though I do not focus on a specific style or genre of dance, my personal experience and reference point derives from a professional career of performing, teaching, and researching Western theatrical concert dance.

5. Erick Hawkins' (1992) concept of "think/feel" as the basis for dance thought is an especially evocative historical example of the fundamentally twined nature of knowing in dance.

6. For a good discussion of related issues in theater studies, see Hart (2006).

7. It is interesting to consider ways that research on the effects of notation on dance cognition (cf., Warburton 2000) may also benefit from the enactive approach. As suggested by Franko (2011), "... the sense of the score-and hence some notion of notation—seems to remain within the body 
and the mind of the dancer as a danced possibility. That is to say, some form of cognitive mapping takes the place of the idea of notation and takes root in the dancer's mind and body (if not on paper)" (328).

8. The implications of mirror neurons were quickly extended to humans. Some scientists argue that humans have a dedicated "mirror neuron area," located around the Broadmann's Area 44 (the human homolog of the monkey F5 region). But more questions about the architecture for embodied cognition have been raised than have been answered. Most scientists working in this area agree that the specifics of the underlying architecture will be one of the defining projects for neuroscience and neurophysiology in the coming years.

9. The word mimicry is derived from the Greek term mimetikos, "imitative," in turn from mimetos, the verbal adjective of mimeisthai, "to imitate."

10. As $D R J$ reviewers noted, this is not the only way to experience, learn, or choreograph dance and may not be true for all kinds of dance. Many contemporary choreographers eschew the command style of choreography, opting for more collaborative approaches. One can also readily imagine, for example, a choreographer who works against any tendency to "move into empathy together." Though I contend that the concept of dance enaction obtains in those kinds of situations as well, I focus on this one aspect for the sake of argumentation and space limitation.

11. It is beyond the scope of this article to discuss in depth the notion of body selfconsciousness and the question of how "an experience can be both and at the same time an experience of one's physicality and of one's subjectivity" (Legrand and Ravn 2009, 389-90). In Thompson's (2005) discussion of the enactive approach to experience, I find a detailed and persuasive solution to the so-called "body-body" problem: "the problem of how to relate one's subjectively lived body to the organism or living body that one is" (408).

\section{Works Cited}

Adolphs, Ralph. 2002. "Neural Systems for Recognizing Emotion.” Current Opinion in Neurobiology 12: $169-77$.

Aglioti, Salvatore M., Paola Cesari, Michela Romani, and Cosimo Urgesi. 2008. "Action Anticipation and Motor Resonance in Elite Basketball Players." Nature Neuroscience 11(9): 1109-16.

Avenanti, Alessio, Domenica Bueti, Gaspare Galati, and Salvatore M. Aglioti. 2005. "Transcranial Magnetic Stimulation Highights the Sensorimotor Side of Empathy for Pain.” Nature Neuroscience 8(7): 955-60.

Baltes, Paul B., Ursula M. Staudinger, and Ulman Lindenberger. 1999. "Lifespan Psychology: Theory and Application to Intellectual Functioning." Annual Review of Psychology 50: 471-507.

Bangerter, Adrian, and Chip Heath. 2004. "The Mozart Effect: Tracking the Evolution of a Scientific Legend." British Journal of Social Psychology 43: 605-23.

Bastiaansen, J. A. C. J., Marc Thioux, and Christian Keysers. 2009. "Evidence for Mirror Systems in Emotions." Philosophical Transactions of The Royal Society Biological Sciences 364(1528): 2391404.

Birringer, Johannes, and Josephine Fenger, eds. 2005. Tanz im Kopf/Dance and Cognition. Münster: LIT Verlag.

Blair, R. James R. 2005. "Responding to the Emotions of Others: Dissociating Forms of Empathy Through the Study of Typical and Psychiatric Populations." Consciousness and Cognition 14: 698718.

Bläsing, Bettina, Martin Puttke, and Thomas Schack, eds. 2010. The Neurocognition of Dance: Mind, Movement and Motor Skills. New York: Psychology Press.

Bläsing, Bettina, G. Tenenbaum, and Thomas Schack. 2009. "The Cognitive Structure of Movements in Classical Dance." Psychology of Sport and Exercise 10(3): 350-60.

Bond, Karen E., and Susan W. Stinson. 2000/01. "II Feel Like I'm Going to Take Off!' Young People's Experiences of the Superordinary in Dance.” Dance Research Journal 32(2): 52-87. 
Brown, Steven, Michael J. Martinez, and Lawrence M. Parsons. 2006. "The Neural Basis of Human Dance." Cerebral Cortex 16: 1157-67.

Calvo-Merino, Beatrice. 2010. "Neural Mechanisms for Seeing Dance." In The Neurocognition of Dance: Mind, Movement and Motor Skills, edited by B. Bläsing, M. Puttke, and T. Schack, 153-76. New York: Psychology Press.

Calvo-Merino, Beatrice, Daniel E. Glaser, Julie Grèzes, Richard E. Passingham, and Patrick Haggard. 2005. "Action Observation and Acquired Motor Skills: An fMRI Study with Expert Dancers." Cerebral Cortex 15: 1243-9.

Calvo-Merino, Beatrice, Julie Grèzes, Daniel E. Glaser, Richard E. Passingham, and Patrick Haggard. 2006. "Seeing or Doing? Influence of Visual and Motor Familiarity in Action Observation." Current Biology 16: 1905-10.

Catmur, Caroline, Vincent Walsh, and Cecilia Heyes. 2009. "Associative Sequence Learning: The Role of Experience in the Development of Imitation and the Mirror System.” Philosophical Transactions of The Royal Society Biological Sciences 364(1528): 2369-80.

Chaiklin, Sharon, and Hilda Wengrower, eds. 2009. The Art and Science of Dance/Movement Therapy: Life Is Dance. New York: Routledge.

Cheever, Olivia. 2000. "Connected Knowing and 'Somatic Empathy' Among Somatic Educators and Students of Somatic Education." ReVision 22(4): 15-23.

Clark, Andy. 1997. Being There: Putting Brain, Body, and World Together Again. Cambridge, MA: MIT Press.

Cohen, Bonnie Bainbridge. 1993. Sensing, Feeling, and Action: The Experiential Anatomy of Body-Mind Centering. Northampton, MA: Contact Editions.

Corcoran, Kevin J. 1981. "Experiential Empathy: A Theory of Felt-Level Experience." Journal of Humanistic Psychology 21(1): 29-38.

Cowen, Nelson. 2000. "The Magical Number 4 in Short-Term Memory: A Reconsideration of Mental Storage Capacity." Behavioral and Brain Sciences 24: 87-185.

Cross, Emily S. 2010. "Building a Dance in the Human Brain: Insights from Expert and Novice Dancers." In The Neurocognition of Dance: Mind, Movement and Motor Skills, edited by B. Bläsing, M. Puttke, and T. Schack, 177-202. New York: Psychology Press.

Cross, Emily S., Antonia Hamilton, and Scott T. Grafton. 2006. "Building a Motor Simulation De Novo: Observation of Dance by Dancers." NeuroImage 31: 1257-67.

Cross, Emily S., Antonia Hamilton, David J. M. Kraemer, William M. Kelley, and Scott T. Grafton. 2009. "Dissociable Substrates for Body Motion and Physical Experience in the Human Action Observation Network." European Journal of Neuroscience 30: 1383-92.

Daly, Ann. 1992. "Dance History and Feminist Theory: Reconsidering Isadora Duncan and the Male Gaze. In Gender in Performance: The Presentation of Difference in the Performing Arts, edited by L. Senelick, 239-59. Hanover, NH: Tufts University/University Press of New England.

Damasio, Antonio R. 1994. Descartes' Error: Emotion, Reason, and the Human Brain. New York: Putnam.

Dana Foundation. 2008. Learning, Arts, and the Brain: The Dana Consortium Report on Arts and Cognition. Washington, DC: Dana Foundation.

de Vignemont, Frederique, and Tania Singer. 2006. "The Empathic Brain: How, When and Why?" Trends in Cognitive Sciences 10(10): 435-41.

Decety, Jean. 2010. "To What Extent Is the Experience of Empathy Mediated by Shared Neural Circuits.” Emotion Review 2(3): 204-7.

Desmond, Jane C., ed. 1997. Meaning in Motion: New Cultural Studies of Dance. Durham, NC: Duke University Press.

Dimberg, Ulf, and Arne Öhman. 1996. "Behold the Wrath: Psychophysiological Responses to Facial Stimuli." Motivation and Emotion 20(2): 149-82.

Donald, Merlin. 1991. Origins of the Modern Mind: Three Stages in the Evolution of Culture and Cognition. Cambridge, MA: Harvard University Press.

Eddy, Martha. 2009. "A Brief History of Somatic Practices and Dance: Historical Development of the Field of Somatic Education and Its Relationship to Dance." Journal of Dance and Somatic Practices 1(1): 5-27. 
Ede, Siân. 2006. Mind, Brain and Performance: Report of a One-Day Symposium Held at Sadler's Wells Theatre. London: Calouste Gulbenkian Foundation.

— 2008. The Embodied Mind: Report of a Symposium Held at the Squire Bancroft Studio, Royal Academy of Dramatic Art. London: Calouste Gulbenkian Foundation.

Engel, Lis. 2008. "Experience of Body/Self as the Primary Ground of Life/Art Creation: A Phenomenological Case Study of Rolfing." Body, Movement and Dance in Psychotherapy 3(2): 107-18.

Fadiga, Luciano, Leonardo Fogassi, Giovanni Pavesi, and Giacomo Rizzolatti. 1995. "Motor Facilitation During Action Observation: A Magnetic Simulation Study." Journal of Neurophysiology 73(6): 2608-11.

Farnell, Brenda M. 1999. “Moving Bodies, Acting Selves.” Annual Review of Anthropology 28: 341-73.

Foster, Susan Leigh, ed. 1996. Corporealities: Dancing Knowledge, Culture and Power. New York: Routledge.

Foster, Susan Leigh. 2011. Choreographing Empathy: Kinesthesia in Performance. New York: Routledge. Fraleigh, Sondra Horton. 1987. Dance and the Lived Body: A Descriptive Aesthetics. Pittsburgh, PA: University of Pittsburg Press.

Franko, Mark. 1995. Dancing Modernism/Performing Politics. Bloomington: Indiana University Press. Franko, Mark. 2002. The Work of Dance: Labor, Movement, and Identity in the 1930s. Middletown, CT: Wesleyan University Press.

- 2011. "Writing for the Body: Notation, Reconstruction, and Reinvention in dance." Common Knowledge 17(2): 321-34.

Franko, Mark, and Annette Richards. 2000. “Actualizing Absence: The Pastness of Performance.” In Acting on the Past: Historical Performance Across the Disciplines, edited by M. Franko and A. Richards, 1-9. Hanover, NH: Wesleyan University Press.

Gallagher, Shaun. 2005. How the Body Shapes the Mind. Oxford, UK: Oxford University Press.

Gardner, Howard. 1985. The Mind's New Science: A History of the Cognitive Revolution. New York: Basic Books.

Gazzola, Valeria, Lisa Aziz-Zadeh, and Christian Keysers. 2006. "Empathy and the Somatotopic Auditory Mirror System in Humans.” Current Biology 16(18): 1824-29.

Gibbs Jr., Raymond W. 2006. Embodiment and Cognitive Science. New York: Cambridge University Press.

Gibson, James J. 1979. The Ecological Approach to Visual Perception. Boston: Houghton-Mifflin.

Goldstein, Thalia R., and Paul Bloom. 2011. "The Mind on Stage: Why Cognitive Scientists Should Study Acting." Trends in Cognitive Sciences 15(4): 141-2.

Golomer, Eveline, Arnaud Bouillette, Caroline Mertz, and Jean Keller. 2008. "Effect of Mental Imagery Styles on Shoulder and Hip Rotations During Preparation of Pirouettes.” Journal of Motor Behavior 40: 281-90.

Golomer, Eveline, and Philippe Dupui. 2000. "Spectral Analysis of Adult Dancers' Sways: Sex and Interaction Vision-Proprioception.” International Journal of Neuroscience 105: 15-26.

Grove, Robin, Catherine Stevens, and Shirley McKechnie, eds. 2005. Thinking in Four Dimensions: Creativity and Cognition in Contemporary Dance. Melbourne, Australia: Melbourne University Press.

Hagendoorn, Ivar G. 2003. "Cognitive Dance Improvisation: How Study of the Motor System Can Inspire Dance (and Vice Versa).” Leonardo 36: 221-7.

- 2004. "Some Speculative Hypotheses About the Nature and Perception of Dance and Choreography." Journal of Consciousness Studies 11(3-4): 79-110.

Hallam, Susan, Ian Cross, and Michael Thaut, eds. 2009. Oxford Handbook of Music Psychology. Oxford, UK: Oxford University Press.

Hanna, Judith Lynne. 1988. Dance, Sex, and Gender: Signs of Identity, Dominance, Defiance, and Desire. Chicago: University of Chicago Press.

Hart, Faith Elizabeth. 2006. "Performance, Phenomenology, and the Cognitive Turn." In Performance and Cognition: Theatre Studies and the Cognitive Turn, edited by B. McConachie and F. E. Hart. New York: Routledge. 
Hawkins, Erick. 1992. The Body Is a Clear Place and Other Statements on Dance. Princeton, NJ: Princeton Book Company.

Jackson, Frank. 1982. Epiphenomenal Qualia. The Philosophical Quarterly 32(127):127-36.

Jola, Corinne, Shantel Ehrenberg, and Dee Reynolds. 2011. "The Experience of Watching Dance: Phenomenological-Neuroscience Duets." Phenomenology and the Cognitive Sciences 10 (2): $1-21$.

Jola, Corinne, and Fred W. Mast. 2005. "Mental Object Rotation and Egocentric Body Transformation: Two Dissociable Processes?" Spatial Cognition and Computation 5: 217-37.

Kimmerle, Marliese, and Paulette Côté-Laurence. 2003. Teaching Dance Skills: A Motor Learning and Development Approach. Andover, NJ: J. Michael Ryan Publishers.

Kirsh, David. 2010. "Thinking with the Body." In Proceedings of the Thirty-Second Annual Meeting of the Cognitive Science Society, edited by R. Catrambone and S. Ohlsson, Austin, TX: Cognitive Science Society.

Kozul, Susan. 2007. Closer: Performance, Technologies, Phenomenology. Cambridge, MA: MIT Press. Lambie, John A., and A. J. Marcel. 2002. "Consciousness and the Varieties of Emotional Experience: A Theoretical Framework." Psychological Review 109: 219-59.

Leckman, James F., Michael H. Bloch, Lawrence Scahill, and Robert King. 2006. "Tourette Syndrome: The Self Under Siege.” Journal of Child Neurology 21(8): 642-9.

Legrand, Dorothée, T. Grünbaum, and J. Krueger. 2009. "Dimensions of Bodily Subjectivity." Phenomenology and the Cognitive Sciences 8(3): 279-83.

Legrand, Dorothée, and Susanne Ravn. 2009. "Perceiving Subjectivity in Bodily Movement: The Case of Dancers." Phenomenology and the Cognitive Sciences 8(3): 389-408.

Leslie, Alan M. 1987. "Pretense and Representation: The Origins of Theory of Mind." Psychological Review 94: 412-26.

McCarthy, Rosaleen, Alan Blackwell, Scott deLahunta, Alan Wing, Kristen Hollands, Philip Barnard, Ian Nimmo-Smith, and Anthony Marcel. 2006. "Bodies Meet Minds: Choreography and Cognition." Leonardo 39(5): 475-7.

McConachie, Bruce. 2006. "Preface." In Performance and Cognition: Theatre Studies and the Cognitive Turn, edited by B. McConachie and F. E. Hart, ix-Xv. New York: Routledge.

McConachie, Bruce, and Faith Elizabeth Hart, eds. 2006. Performance and Cognition: Theater Studies and the Cognitive Turn. New York: Routledge.

McFee, Graham. 1992. Understanding Dance. London: Routledge.

Merleau-Ponty, Maurice. 1962. Phenomenology of Perception. Translated by C. Smith. London: Routledge.

Orgs, Guido, Jan-Henryk Dombrowski, Martin Heil, and Petra Jansen-Osmann. 2008. "Expertise in Dance Modulates Alpha/Beta Event-Related Desynchronization During Action Observation." European Journal of Neuroscience 27(12): 3380-4.

Parviainen, Jaana. 1998. Bodies Moving and Moved: A Phenomenological Analysis of the Dancing Subject and the Cognitive and Ethical Values of Dance Art. Tampere, Finland: Tampere University Press.

— 2002. "Bodily Knowledge: Epistemological Reflections on Dance." Dance Research Journal 34(1): 11-26.

Pfeifer, Rolf, and Christian Scheier. 1999. Understanding Intelligence. Cambridge, MA: MIT Press. Phelps, Elizabeth A. 2006. "Emotion and Cognition: Insights from Studies of the Human Amygdala." Annual Review of Psychology 57: 27-53.

Piaget, Jean. 1952. The Origins of Intelligence in Children. Translated by M. Cook. New York: International Universities Press. Original edition, 1936.

Press, Carol M. 2002. The Dancing Self: Creativity, Modern Dance, Self Psychology, and Transformative Education. Cresskill, NJ: Hampton Press.

Press, Carol M., and E. C. Warburton. 2007. "Creativity Research in Dance." In International Handbook of Research in Arts Education, edited by L. Bresler, 1271-86. New York: Kluwer/Springer. Prinz, Jesse J. 2002. Furnishing the Mind: Concepts and Their Perceptual Basis. Cambridge, MA: MIT Press. 
Ramsey, Jill R. E., and M. Jane Riddoch. 2001. "Position-Matching in the Upper Limb: Professional Ballet Dancers Perform with Outstanding Accuracy." Clinical Rehabilitation 15: 324-30.

Reason, Matthew, and Dee Reynolds. 2010. "Kinesthesia, Empathy, and Related Pleasures: An Inquiry into Audience Experiences of Watching Dance.” Dance Research Journal 42(2): 49-75.

Reed, Susan A. 1998. "The Politics and Poetics of Dance." Annual Review of Anthropology 27: 503-32.

Rizzolatti, Giacomo, Luciano Fadiga, Vittorio Gallese, and Leonardo Fogassi. 1996. "Premotor Cortex and the Recognition of Motor Actions." Cognitive Brain Research 3: 131-41.

Rothfield, Philipa. 2005. "Differentiating Phenomenology and Dance." Topoi 24(1): 43-53.

Rouhiainen, Leena. 2003. Living Transformative Lives: Finnish Freelance Dance Artists Brought into Dialogue with Merleau-Ponty's Phenomenology. Helsinki: Theatre Academy.

- 2008. "Somatic Dance as a Means of Cultivating Ethically Embodied Subjects." Research in Dance Education 9(3): 241-56.

Ryle, Gilbert. 2000. The Concept of Mind. Chicago, IL: University of Chicago Press.

Schack, Thomas. 2004. "The Cognitive Architecture of Complex Movement." International Journal of Sport and Exercise Psychology; Special Issue Part II: The Construction of Action-New Perspectives in Movement Science 2(4): 403-38.

Schack, Thomas, and F. Mechsner. 2006. "Representation of Motor Skills in Human Long-Term Memory.” Neuroscience Letters 391: 77-81.

Searle, John R. 2004. Mind. New York: Oxford University Press.

Shapiro, Sherry B., ed. 1998. Dance, Power, and Difference: Critical and Feminist Perspectives on Dance Education. Champaign, IL: Human Kinetics.

Sheets-Johnstone, Maxine. 1966. The Phenomenology of Dance. New York: Books for Libraries (reprint ed., 1980).

- 1999. The Primacy of Movement. Amsterdam: John Benjamins.

- 2009. The Corporeal Turn: An Interdisciplinary Reader. Exeter, UK: Imprint Academic.

Singer, Tania, and C. Lamm. 2009. "The Social Neuroscience of Empathy." The Year in Cognitive Neuroscience 2009: Annual of New York Academy of Science 1156: 81-96.

Solso, Robert L. 1994. Cognition and the Visual Arts. Cambridge, MA: MIT Press.

Stevens, Catherine, and Shirley McKechnie. 2005. "Thinking in Action: Thought Made Visible in Contemporary Dance." Cognitive Process 6: 243-52.

Stewart, Nigel. 1998. "Re-Languaging the Body: Phenomenological Description and the Dance Image." Performance Research 3(2): 42-53.

Stock, Armin, and Claudia Stock. 2004. "A Short History of Ideo-Motor Action.” Psychological Research 68: 176-88.

Thelen, Esther, and L. B. Smith. 1994. A Dynamic Systems Approach to the Development of Cognition and Action. Cambridge, MA: MIT Press.

Thioux, Marc, Valeria Gazzola, and Christian Keysers. 2008. "Action Understanding: How, What and Why." Current Biology 18(10): R431-4.

Thompson, Evan. 2005. "Sensorimotor Subjectivity and the Enactive Approach to Experience." Phenomenology and the Cognitive Sciences 4: 407-27.

Varela, Francisco J., Evan Thompson, and Eleanor Rosch. 1991. The Embodied Mind: Cognitive Science and Human Experience. Cambridge, MA: MIT Press.

Warburton, Edward C. 2000. "The Dance on Paper: The Effect of Notation-Use on Learning and Development in Dance." Research in Dance Education 1(2): 193-213.

— . 2003. "Intelligence Past, Present, and Possible: The Theory of Multiple Intelligences in Dance Education." Journal of Dance Education 3(1): 7-15.

- 2004. "Knowing What It Takes: The Effect of Perceived Learner Advantages on Dance Teachers' Use of Critical-Thinking Activities." Research in Dance Education 5(1): 69-82.

_ 2010. "Toward Varieties of Empathetic Experience in Dance." Paper read at the Cognitive Science in Theatre and Performance Working Group for "Embodying Power: Work Over Time," a joint conference of the American Society for Theatre Research, Congress on Research in Dance, and the Theatre Library Association, November 18-21, Seattle, Washington. 
Welsh, Anne Marie. 2009. "Body Language Put into Words." Los Angeles Times, March 8, E1.

Wildschut, Liesbeth. 2010. "Moving While Watching Dance." Paper read at Watching Dance: Kinesthetic Empathy conference, at Manchester, United Kingdom.

Willerslev, Rane. 2004. "Not Animal, Not Not-Animal: Hunting, Imitation and Empathetic Knowledge Among the Siberian Yukaghirs." Journal of the Royal Anthorpological Institute 10: 629-52.

Williams, Drid. 1991. Ten Lectures on Theories of the Dance. Metuchen, NJ: Scarecrow Press.

Wilson, Margaret. 2001. "Sign Language Expertise and the Perceived Path of Apparent Motion."

In Context, Cognition, and Deafness, edited by M. D. Clark, M. Marschark, and M. Karchmer, 38-48. Washington, DC: Gallaudet University Press.

2002. "Six Views of Embodied Cognition." Psychonomic Bulletin and Review 9(4): 625-36.

Ziemke, Tom. 2001. "Disentangling Notions of Embodiment." Paper read at Workshop on Developmental Embodied Cognition, July 2001, Edinburgh, UK. 


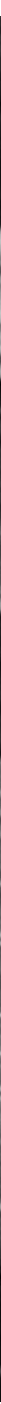

